\title{
EDUCATIONAL CRISIS MANAGEMENT REQUIREMENTS AND ITS RELATION TO USING DISTANCE LEARNING APPROACH: A CROSS-SECTIONAL SURVEY SECONDARY STAGE SCHOOLS IN AL-BALQA'A GOVERNORATE DURING COVID-19 OUTBREAK FROM THE PERSPECTIVES OF TEACHERS
}

\author{
Dr. Fadi SAMAWI \\ ORCID: 0000-0001-9561-7473 \\ Department of Educational Sciences \\ Al-Balqa Applied University \\ Al-Salt, JORDAN
}

Received: 25/06/2020 Accepted: 23/12/2020

\begin{abstract}
The current study aimed at investigating the educational crisis management and its relation to using distance learning approach in secondary stage schools in Al-Balqaa governorate during COVID- ' 19 outbreak from the perspectives of teachers. A random study sample consisted of 10 male and female teachers from 30 different secondary stage schools was recruited in this study. A researcher developed questionnaire consisted of 54 items was adopted in this study. The questionnaire items were examining the educational crisis management requirements (36 items) and the distance learning (18items). Data processing was performed using the Statistical Package of Social Sciences (SPSS). The results indicated that the educational crisis management requirements ranged between (3.72-3.93) that are at high levels, where the planning domain was ranked first with the highest mean score of (3.93), followed by leadership skills with a mean score of (3.78) And in the third rank was the information domain with a mean score of (3.75), and in the fourth rank was the communication domain with a mean score of (3.73), finally in the last rank was the team work with a mean score of (3.72). the results related to distance learning indicated that the mean scores ranged between (3.563.64) at moderate levels, so that the rationale for distance learning method domain got the highest mean score (3.64), followed by the importance of distance learning method with a mean score of (3.62), and in the third and last rank was the obstacles of the distance learning method with a mean score of (3.58). The total mean score for the distance learning method was (3.59) and a standard deviation (.687), and with moderate level. Finally, the results showed the positive and significant role of the requirements of educational crisis management in its five domains (planning, information, communications, leadership skills, team work) in raising the level of use of the distance learning method in its three domains (the importance of distance learning, the rationale for distance learning, and the obstacles to distance learning) among male and female teachers of secondary schools in Al Balqaa governorate.
\end{abstract}

Keywords: Secondary stage, educational crisis management, distance learning, crisis management.

\section{INTRODUCTION}

Crises, whatever their severity, they awaken humans from their negligence and generate new business models that they would not have moved to if they continued to practice their lives with the usual routine. Today, in the midst of the horrific and mysterious talk about the fate of the world in light of the spread of the COVID-19 outbreak, there is no doubt that it represents a crisis like any crisis that shakes the world and Its results will be are distinctive innovations and methods, and it will change the mindsets that would not have passed from one stage to another without the necessity of the crisis. Among the precautionary measures to control the emerging COVID-19 outbreak and limit its spread, some countries of the world, including Jordan, announced the suspension of the study for a specified period, or indefinitely, and here began to 
increase Talking about the distance e-learning as one of the crisis management practices, the extent of its effectiveness and the necessary preparations to implement it in a way that guarantees its efficiency, continuity and positive interaction of students with it.

The science of crisis management is considered one of the modern sciences whose importance has increased in the present day and which witnessed many overlapping variables, whether at the international, regional, national or local level, it is one of the future sciences, the science of adapting to changes, the science of kinetics and the forces of action in all human fields, Whether it is economic, social, cultural or other. Thus, it is an independent science in itself, which - at the same time - is connected to all other humanities and takes from and adds to it the new that it needs (Al-Khudairi, 2003).

The crisis is a clear indication of the existence of a defect in society, and it needs to be faced with scientific methods in order to restore society to its natural balance. The crisis is related to terms such as: according to Bandy and Cole and Coombs (2017):

Crisis: a critical period or unstable condition awaiting a critical change, which is pain or dysfunction.

Crisis Management: A special management process that will produce a strategic response, to crisis situations, through a group of pre-selected and well-trained managers, who use special skills and procedures to reduce losses.

The crisis includes several stages within it, which are, as Kamei (2019) pointed out:

The first stage: It is the stage of birth and emergence of the crisis, and it needs the expertise of the decisionmaker to get to know the crisis and find solutions to it.

The second stage: the stage of expansion and growth of the crisis: a stage that begins when the decisionmaker fails to face the crisis and includes the presence of internal and external nutrients that increase the strength of the crisis.

The third stage: the summit stage of the maturity of the crisis: This stage is rare, but it is increasingly underestimated and inexperienced, as the crisis becomes highly destructive.

The fourth stage: the decline and shrinkage stage: It is not a final stage, but within the procedures followed, the crisis begins with regression and contraction.

Fifth stage: the disappearance of the crisis: the crisis loses all manifestations of strength and momentum, begins to fade, and society begins to recover.

School administration needs a methodology for diagnosing crises, through knowledge, practice, and experience, the most important of which is the abundance of information and data for decision makers, as the diagnosis process is the real key to dealing with the crisis, and without it, dealing with crises becomes only an improvisational process (Hilali and Dabbous, 2011).

In view of the seriousness of the results that come out from crises of all kinds, educational institutions strive to utilize different strategies, emphasizing involvement with personnel in the educational facility or schools, and shared leadership to think, implement, follow-up and evaluate, and activate this via the formation of boards and work groups and organization of data about crises, besides to prepare and train employees on confronting them (Al-Zamili et al., 2007).

Dealing with crises requires the presence of a special type of managers, teachers and administrators who are adequately trained, to refine their skills, talents and natural readiness, as dealing with crises has a special character that derives its specificity from the effect of future momentary factors with their confrontational dimensions, as well as the possibilities of deteriorating conditions in a very strong way (Hamdouneh, 2006).

To confront crises, modern methods are varied and appropriate to the spirit of the times and are compatible with the nature of its variables such as the method of confronting the crisis in an organized scientific way (AlMahdi and Wahiba, 2002), and the method of the team work where everyone cooperates in facing the crisis, and each member has his tasks that he performs, and the method of containing the crisis is done through the restricting of the crisis and Freezing it at the stage it has reached, and working to absorb the pressures that generate it, and then losing its destructive power (Ahmed, 2002). 
The educational crisis is an unusual turning point, which is the situations that the school is exposed to suddenly and events happen quickly and causes are intertwined with results. In addition, it results in a threat to property, values and possibly for lives, and also results in anxiety and stress for all members of the school, which leads the school administration to control on these situations and rational decision-making (Abu Khalil, 2001).

The educational crisis is defined as a critical period in which various events are intertwined, which creates a state of imbalance among decision makers, causing an imbalance in thinking as a result of the accumulated pressures, resulting in a misuse of available alternatives and the failure to invest powers and capabilities, which leads to undesirable outcomes in the educational institution (Hamdouna, 2006)

While educational crisis management is defined as the unceasing administrative processes that are concerned with predicting possible crises, keeping an eye on both internally or externally sourced variables creating the crisis and exploiting the accessible resources and capabilities to mitigate or deal with the crisis at the greatest degree of effectiveness and professionalism, in a manner that achieves the least damage to the educational institution, the environment, and workers, while ensuring return To normalcy as soon as possible, and at the lowest possible cost, as well as studying the forces and factors behind the crisis to prevent it from happening again (Mustafa, 2005).

The educational crisis passes through several stages, which are the core of the educational crisis, which represents the focus of the educational crisis as its internal and external source. The stage of creating a climate or its availability, as the forces that create the educational crisis are working to create a favorable climate that encourages the growth, exacerbation, and intensification of the temporal pressure, the use of catalysts, the stage of overlooking the signs of the educational crisis forces, the stage of the prevalence of tensions and anxiety, the occurrence of the prospective factor, and the explosion of the educational crisis (Ghunaimah, 2014)

The approach to educational crisis management is based on a scientific method, requiring the leader of the educational crisis or the director of the educational institution to follow the administrative processes of planning for managing educational crises, organization in the management of educational crises, guidance in educational crises, follow-up of educational crises, the information system in educational crises, system Communication in educational crises, and the availability of leadership skills in managing educational crises (Elewah, 2004; Abu Khalil, 2001; Al-Taweel, 2006; Al-Omar, 2003; Hamdona, 2006).

The significance of crisis management emerges through the provision of the methodological capabilities for extrapolation and prediction of the real and possible threats source, and optimize the available resources and skills to minimize the consequences of the crisis, in addition to provide practical skills and substantial abilities in preparing and confronting, and working to go back to the normal situation via a group of recovery actions and procedural activities (Al-Sheikh, 2008).

The Jordanian Ministry of Education had previously introduced computers and the Internet and used them in Jordanian schools as one of the necessities to keep abreast of developments and innovations, and to create an interactive teaching-learning environment, containing curricula in addition to many other tasks (Salem, 2007). It began to establish an e-learning system in cooperation with the Integrated Technology Group Company; to be the first step to take advantage of the Internet in the educational process, so that this project serves more than 3,200 schools, including more than one million six hundred thousand students from all levels of education (Integrated Technology Group, 2006).

The term distance learning has generally achieved wide popularity; especially since the beginning of the late sixties of the twentieth century, when UNESCO began to take interest in adopting new formulas in the field of adult education and continuous education, and the names of distance learning are multiple, so we find that its multiple names as Distance Learning, and in other cases Distance Teaching, and Distance Education in other areas (Shery, 2004).

Distance education is one of the manifestations of educational development and renewal, whose features began to take shape from the end of the sixties, and this pattern of school education imposed its presence in the educational circles as one of the effective solutions capable of providing more educational opportunities for large sectors of individuals who could not - for one reason or another. - benefit from these opportunities 
through traditional universities, and this has been demonstrated by UNESCO studies on distance education as one of the most developed fields in the recent period, as a result of the rapid development of information and communications technology and its implications in the field of education, as well as in the field of design and delivery of education systems through the Internet, in addition to the increasing social demand for school education in response to the demands of development plans (Al-Sunbul, 2001).

In general, the spread of distance learning is due to three basic factors represented in the increased demand for this type of education, the need to reduce the economic costs of education, as it does not require a large number of employees and needs less educational equipment than traditional school education, and the invasion of modern media and communication technology in various areas of life Including education, through which many social strata could be reached that would not have been able to study in the familiar traditional style (Tony, 1991).

Distance learning is defined as an attempt to deliver an educational service to the individual where he resides or works, and it is specifically directed to groups that are willing and able to learn (Ismail, 2003), while the United States Distance Learning Association (USDLA (2004) defines it as the process of acquiring knowledge and Skills through a medium to transfer education and information, including all types of technology and different forms of learning for distance learning.

Distance education is a method of self-education, which is an advanced education compared to the traditional or school education - led to the strengthening of the open education system, and it is considered a development of the correspondence learning system, and an effective method in providing learning opportunities and enriching experiences for workers who cannot stop work and devote to learning, who were denied from formal education (Al-Kloob, 1993).

The distance learning system is considered a systematic and organized educational system, in which the educational process is accomplished without an actual meeting between the teacher and the learner, that is, the educational body (university, school, teacher) accredits the learner (within) a specific curriculum and special conditions (and gives him a certificate if he fulfills their requirements). As for why we said that it is a formal education, because the learner keeps in constant contact with the educational institution through its study / educational centers, and is subject to continuous follow-up and evaluation by it (Hassaneen, 2004).

Sherry (2001) emphasizes that distance learning is a set of teaching and educational strategies (or teaching methods) to overcome spatial or temporal separation between faculty members and learners, and also affirmed that all of them share the separation between the learner and the teacher, whether spatially, temporally or both together, controlling education is through the learner more than the teacher, and the communication between the student and the teacher via printed materials or other forms of technology.

Simpson puts some types of abilities necessary for the learner to succeed as a distance-learning learner including intelligence, motivation, the ability to seek help, self-confidence, anxiety about tests, the ability to deal with work stress, the ability to do family responsibilities during the study, the ability to Provide a good academic environment, ability to classify study priorities according to importance, and the ability to accept constructive criticism (Al-Saadat, 2002).

Abdel Aziz (2008) mentioned a number of features that distinguish the method of distance education from other types, including: it provides learning at any time and in any place, helps students to rely on themselves; this encourages their independence, gives them the freedom and the boldness to express themselves compared to traditional education, and students can browse educational content and their curricula anywhere and anytime, and they can communicate with their teachers through multiple communication methods such as e-mail, and the student gets immediate feedback where the process of self-constructive and final evaluation is available, and learning resources vary through links with other educational sites.

Despite the importance of distance education, and the initial results that proved its success, this type of education, like other methods of education, faces some obstacles and challenges in its utilization. Al-Oraifi (2003) indicated that the low educational quality, the cost of development, the lack of national plan, the limited content in the market, and the absence of human interaction are of the most important barriers to distance learning. 
As for the obstacles and challenges facing educational institutions in Jordan and limit the utilization of e-learning as viewed by Bani Doumi and Al-Shannaq (2006) and Khazaleh and Jawarneh (2007) are represented in the weakness of the effectiveness of teacher training programs in the field of information technology, and the lack of school students' acquisition of Basic information technology skills and competencies, technical problems that appear in computers and the Internet, the computer lab not being equipped with the necessary printers, headphones and printing paper, and the student does not have a computer at home.

The procedures for planning distance learning programs are represented by inclusiveness, cooperation, commitment, and continuity, as well as knowing the social values surrounding the learners, setting goals, means and methods of application, educational means, the teaching staff, and providing appropriate funding and facilities to assist the learning process, evaluation methods, and continuous access to feedback (Picciano, 2001).

Academic and non-academic support comes from providing advice and guidance, clarifying concepts and goals, following the progress of the learner, providing practical assistance to advance the learning process, assisting in social and employment activities, and providing educational support services to achieve feedback to those who are responsible of distance education, and this is achieved mainly through bilateral communication between the learner and the educational institution (Simpson, 2000).

Accordingly, distance learning has special benefits and importance for school learning, as it is necessary to identify the characteristics of the target audience, determine the goals of the programs, define teaching methods and appropriate educational methods, choose qualified teachers and administrators, and appropriate evaluation methods. So, this study sought to explore the perspectives of secondary stage school students in $\mathrm{Al}$ Balqa'a governorate regarding their ability to identify the requirements of educational crisis management during COVID-19 outbreak and its relation to utilizing distance-learning approach.

\section{Previous Studies}

Adams \& Kritsonis (2006) conducted a study aimed at analyzing crises for secondary schools. The study targeted crisis management plans in schools that have experienced crisis situations in the past. The researchers used the descriptive approach, and administered a questionnaire to (23) schools in Houston. The most significant outcome of this study was providing schools with Extensive roles in crisis management, planning more effectively when schools are in crisis, and assessing school level through preparedness stage.

Ryan (2007) study aimed to measure the impact of social networks on achievement and cognitive perception towards cooperation at the middle school level, and used the quasi-experimental approach, over a random sample of 400 students, divided into four groups (50 per group), two experimental groups and two control groups. The study found that there were no differences in achievement between groups, with a statistically significant difference in cognitive perception towards cooperative work in favor of experimental group referred to the gender variable in favor of females, and there were no significant differences in use referred to the class variable.

The study of Al-Hersh, Mufleh, and Al-Dahoon (2010) aimed to explore the obstacles to using the distance learning system from the viewpoint of secondary school teachers in the district of Koura. The results indicated that the obstacles related to the teachers were ranked first, followed by the obstacles related to management, then the obstacles related to the infrastructure and the basic equipment, and the obstacles related to the students were in the last rank, whereas there were no differences referred to the effect of the training courses in all domains.

Hilali and Dabbous (2011) conducted a study aimed at identifying educational crises in public secondary schools in Palestine and how to manage them from the perspectives of principals. The qualitative approach was used by interviewing the sample (50) male and female principals in the governorates of northern Palestine, as they are suitable for this study. The study found that educational crises in public secondary schools in Palestine are divided into two parts, the first of which is general crises, which are the occupation crisis, the curriculum crisis, the teachers crisis, the students crisis, the relationship crisis with the local community, 
the school building crisis, on the other hand, the second section is special crises, related to each principal separately, the principals of public secondary schools adopt traditional methods and situational leadership in their management of crises by trying to control the crisis as much as possible.

Ghunaima (2014) conducted a study aimed at identifying the requirements of educational crisis management (material, administrative, and human) in secondary schools in the city of Damascus, and the most important crises facing them, using the descriptive analytical approach. The study sample consisted of (55) male and female principals, and a questionnaire consisted of (70) items was developed. The questionnaire items were distributed on five domains: (planning domain, information domain, communication systems domain, leadership skills domain, team work domain). The study reached the great significance of the availability of educational crisis management requirements in secondary schools in the city of Damascus with high and close degrees.

Khubrani (2014) conducted a study aimed at identifying the methods of managing school crises in the stages of public education, and the obstacles to their use in the city of Makkah Al-Mukarramah from the point of view of school principals. The descriptive approach was used, the study sample consisted of (21) principals from secondary schools, and (38)) principals of middle schools, and (70) principals of primary schools. The study revealed that the most important methods of crisis management are the scientific followed by the team work method and that the most prominent obstacles facing the use of crisis management methods are: the large number of tasks assigned by the school principal and the routine nature related to it. In addition to the lack of a comprehensive database in the field of school crisis management.

Al-Sharhan (2014) conducted a study to shed light on the areas of open learning and distance learning in the Arab world, and to determine the extent of the need for it towards development and creativity. The study presented some experiences in the Arab countries and a review of the difficulties and challenges facing them, and the study presented a scientific model for building and developing it in the Arab world, a model for developing teaching skills, and a model for the comprehensive quality management of open and distance learning.

Al-Hajri (2016) conducted a study that addressed the attitudes of the faculty staff and students in the secondary education stage in the State of Kuwait towards their awareness of the importance of applying the e-learning method as a tool for developing education, the availability of the competencies of e-learning for them, and used the descriptive analytical approach. the sample consisted of (423) male and female school principals, and (463) male and female students, and the study concluded that there are positive attitudes for both the faculty members and students towards their awareness of the importance of applying the e-learning method as a tool for developing education, and that there is a positive correlation between the competencies of e-learning for each of the faculty members and students and their awareness of the method of e-learning as a tool for Education development.

Sabbah (2020) assessed the e-learning and information and communication technology in primary and secondary education in Palestine in the light of the initiatives that schools pursue in e-learning curricula. The results showed a shift in teachers and students' behavior, and active learning strategies made education more effective and enjoyable. The teachers indicated that they still need more training in the skills of the twenty-first century, and that educational policies should encourage the implementation and generalization of these skills at the national level and work to reform educational curricula and provide motivation, support and training for teachers.

\section{Statement of Problem}

Sometimes, the circumstances and crises that we face lead us to invest the available tools and enhance them to reach the desired goals. In light of the global attempts to limit the spread of the COVID-19 outbreak, for example, we find that specific countries, including Jordan, have taken many preventive measures in the face of the outbreak by closing schools and universities and places of gathering of students all over the country, and for the continuation of the educational process, it has been announced by educational institutions that they provide distance e-learning platforms as an effective tool for easy access to them from anywhere, which allows students to complete their studies via the Internet, as an opportunity to experience this new 
feature, and invest it to raise the awareness of the exploitation of tools available across various e-learning platforms, and to enhance the skill of research and access to knowledge easily. In spite of the multiplicity and variability of crises and the characteristics of each of them with their distinctive features, they need material, administrative and human requirements to manage them in line with their nature, so the success of educational crisis management depends on them. All these crises are subjected to a scientific collaborative methodology in their management in order to avoid and reduce their negative complications.

As neither the students nor teachers imagined that distance education would become part of their diaries, which was not until recently common or preferred by many in the world, and therefore government and private schools have resorted to the technology of "distance education" through educational sites on the Internet and Social media applications, as a necessary step taken by the Ministry of Education to continue the march despite the current circumstances. The idea of distance learning is based on several methods, including explaining lessons via video conversation between the teacher and students at certain time points, and through voice communication technology only, or by communicating lessons to students through social media applications such as "WhatsApp" in pdf or word files.

The educational crisis appears when there is an inconsistency between the educational crisis and the external environment, at a time when the local community is keeping pace with the technical and technological changes and developments and the era of knowledge and communications and in various fields of life, we find that the educational system stands helpless at times or may not be fully prepared In order to face the crises striking the country, which is represented in our study by the COVID-19 outbreak, which causes crises that hinder the progress of the educational process.

The issue of crisis management in educational institutions has received great attention from researchers and authors in the western environment, and the many studies that addressed it. These studies stressed the necessity of the existence of a working team qualified to encounter, manage, and analyze the plans of the crises management and their interactions. A study conducted by Keung (2008) focused on the domains assisting the school principals in involving the school teachers in decision making process and dealing with crises, and Adams \& Kritsonis (2006) study emphasized the analysis of crisis management plans within schools that have faced crises in the past, while Arab studies in crisis management are constantly increasing as Saqr (2009) study, Hamdouna (2006) and Al-Mousa, (2007) study, all of which aimed to uncover the crises facing school principals and ways to solve them, and to train principals on successful patterns of crisis management.

In spite of the efforts exerted by the Jordanian Ministry of Education to develop the educational process in the Kingdom's schools, and by virtue of the researcher's work in the educational field and his expertise in many issues related to the educational field, especially during this difficult period that the countries of the world, especially Jordan, are going through in encountering COVID-19 outbreak and its effects in the educational field In particular, this study came to explore their perspectives regarding the requirements of educational crisis management and its role in raising the level of use of the e-learning method remotely, the problems faced by high schools in such circumstances and the extent of their ability to manage them, as the researcher believes that there are difficulties and obstacles facing the process of crisis management Including, but not limited to, the low level of awareness among the principals and elements of the educational process of the significance of crisis management within the educational institution, the lack of their skills in crisis management, or the absence of crisis management plans, methods and mechanisms necessary to deal with educational crises, and to address important issues that are summarized by the following study questions:

1. What are the requirements of educational crisis management and its association to adopting distance learning method at secondary schools in Al Balqa'a governorate from the teachers' point of view?

2. What is the level of applying the distance learning method by the secondary schools in Al Balqa governorate during the COVID-19 outbreak from the teachers' point of view?

3. Is there a correlation between the requirements of educational crisis management and the method of distance learning during the COVID-19 outbreak from the teachers' point of view? 


\section{Research Significance}

The importance of the study is to shed light on the concept of educational crisis management during COVID-19 outbreak and explain its role in raising the level of distance learning for public and private high schools from the teachers point of view, because of their importance and specificity in the field of educational management, and raising their levels and strengthening them, and giving them the skills and methods that develop these aspects, and therefore the study acquires its importance from two aspects:

First: Theoretical significance

The importance of the subject of the study and the variables of the study given the distinction of this type of studies in terms of scarcity in dealing with the study variables combined, the fact that the results of the current study are reflected in an important category, which are high school students, and contribute to increasing the awareness of school leaders and secondary school teachers of the importance of planning to manage the crises of our time as a science that has special origins and rules in the field of education and specifically in our schools, and its importance is gained in that the educational system if it does not break into the difficulties and crises that society encounters or approaches study and application, then this leads to serious negatives, and opens the way for researchers studying future studies in this field are dependent on the results of the current study and the recommendations it will provide.

Second: The practical significance

Providing the Arab library with this diverse scientific knowledge, and applied models; So that specialists and researchers can refer to and employ them in educational preparation programs in the Arab world, and contribute to enriching one of the important fields in the field of educational and administrative studies, namely, the management of educational crises and distance learning, and the principles of educational crisis management and the method of distance learning contribute to providing methodological and procedural frameworks that help In setting training programs for high school leaders in various educational regions, and to draw the attention of officials and policy makers in the Jordanian Ministry of Education to the importance of disclosure and direct their administrative practices in this context.

\section{Research Aims}

Clarifying the concept of both educational crisis management and distance learning, and clarify the requirements of educational crisis management during COVID-19 outbreak in secondary schools in Al Balqa' a governorate, and determine the level of secondary schools' application of the method of distance learning during COVID-19 outbreak as a method for managing educational crises, and determine the relationship between the educational crisis management requirements and the distance learning method among the participants in the study sample.

\section{Conceptual and Operational Definitions}

Educational crisis management: a state of imbalance and turmoil leading to a disruption in the daily educational system, hinders the attention of its employees from performing their work, and threatens its continuity in the ability to achieve educational goals and requires immediate measures to prevent their exacerbation, and works to return matters to their normal position (Ghunaima, 2014). procedurally defined: it is the degree to which the study sample gets through their response on the scale of educational crisis management, which includes (36) items distributed on the following domains: planning (7) items, information (7) items, communications (7) items, Leadership skills (8) items, and team work (7) items.

Distance learning: It is a teaching process that is related to the scientific content and its electronic submission to the learner via multimedia on computers and the information network, so that meaningful and active interaction with the course takes place at any place and time the learners chooses and at a speed that is commensurate with his capabilities, and it is an organizational administrative process related to employing a mix of educational media and Work teams on running a course management system (Zeiton, 2005). Procedurally, It is defined as the degree which the study sample participants obtain through their response to the distance learning scale that includes (18) items distributed over the following three domains: the 
importance of using the distance learning method ( 5 items), and the justifications for using the method of distance education ( 8 items), and the obstacles to using the method of distance learning ( 5 items). This scale was developed by the researcher.

\section{Research Limitations}

The human, spatial and temporal study limits are represented by the following: secondary school teachers Al-Balqa Governorate, for the second semester of the academic year 2019/2020

The findings of the study are limited to the psychometric properties of the research tool, and the seriousness of the study sample in response to the study tools.

\section{RESEARCH METHODOLOGY}

The descriptive correlational approach was adopted in the current study. Correlational research seeks to discover if two variables are associated or related in some way. A variable is a characteristic that everyone has but different people have different values. So, for example everyone has an age but different people have different ages. If two variables are correlated, then that means knowing one allows to take an educated guess about what the other one is likely to be. In this study, the requirements of the educational crisis management and using distance learning were studied using the descriptive correlational approach.

\section{Research Population and Sample}

The study population consisted of all male and female secondary school teachers, either in public or private schools, in Al Balqa governorate, which numbered (30) schools distributed by districts (Al-Salt main district, the district of Deir Alla, the district of Fuheis and Mahes, Ain al-Basha district, the central region, the southern region, the district of Southern Shouneh).

As for the study sample, a stratified sample consisting of public and private secondary schools for males and females in Al-Balqa'a Governorate districts was selected equally, as two secondary schools were chosen from each sector (public, private) in each district, i.e. (10) schools, two private schools (secondary), two public schools (secondary), so that, the number of public secondary schools (5), and private secondary schools (5), of which (5) schools for females and (5) schools for males, to represent the study sample from schools in the governorate districts as a prelude to choosing the study sample from The teachers (male and female). the number of secondary school teachers in the study sample schools, counted (112) male and female teachers, and the questionnaires were distributed to them electronically, where the teachers' e-mails were requested from Al-Balqa'a Education Directorate for, and the questionnaire was distributed electronically to the teachers' emails during the period 10-21 / 5/2020, as the number of questionnaires that were retrieved was (109) questionnaires that are valid for the analysis process, i.e. (97\%) of the original sample by (57) male teachers, (52) female teachers.

\section{Research Instrument}

With reference to many of the literature and previous studies related to the topic of the study as well as some tests for measuring educational crisis management and tests for measuring distance learning, a scale was developed based on the study of Ghunaima (2014) and Khubrani (2014) to measure the management of educational crises, and the study of both Al-Hajri (2016) and Sabbah (2020) Al-Harsh, Mufleh, Al-Dahoon (2010) and Al-Saadat (2002) to measure the level of application of distance learning method for secondary school teachers from their point of view. In its primary version, the scale consisted of 54 items distributed over two domains, as follows: the first is the domain of educational crises managements that included 36 items distributed on four domains, and the second: distance learning domain that included (18 items distributed over three domains. It was taken into consideration that the items should be as appropriate as possible and comprehensive to what is included in the concepts of the study, and it is a type of self-report answered by teachers in the light of the five-point scale: Always (5), often (4), sometimes (3), rarely (2) never 
(1), knowing that all items will be positively formulated, and the following equation will be used to extract the range for each of the three levels: (upper category - lower category) / , i.e. (5-1) Divided by (3) equals (1.33), therefore: (1-2.33) is a low level, $(2.34-3.67)$ is a moderate level, and (3.68-5) is a high level.

\section{Validity of the Research Instruments}

- Content validity: The tool was presented to (5) specialists in the field of education and psychology, and their opinions were taken on the appropriateness of the domains and items, the integrity of its language, and based on their observations and their observations, the scale items were modified, or deleted.

- The validity of the internal consistency: items' correlation coefficients were extracted from the overall scale and in the domains to which they belong to extract the significance of the validity of the internal consistency of the scale through a pilot sample from outside the study sample $(\mathrm{n}=25)$ male and female teachers to identify whether the scale is valid and appropriate to achieve the purposes of the current study. The correlation coefficients for the domains of educational crisis management with the tool as a whole ranged between (0.372-0.801), and with the domain between (0.367-0.820), In addition, the correlation coefficients for the domains of distance learning ranged between (.695-.331) with the tool as a whole, and with the domain between (.723 - .395). Table (1) and (2) show that:

Table 1. Correlation coefficients between items, their domains and the total educational crises management scale score

\begin{tabular}{ccccccccc}
\hline Item \# & $\begin{array}{c}\text { Correlation to } \\
\text { the scale }\end{array}$ & $\begin{array}{c}\text { Correlation to } \\
\text { the domain }\end{array}$ & Item \# & $\begin{array}{c}\text { Correlation to } \\
\text { the scale }\end{array}$ & $\begin{array}{c}\text { Correlation to } \\
\text { the domain }\end{array}$ & $\begin{array}{c}\text { Item } \\
\#\end{array}$ & $\begin{array}{c}\text { Correlation } \\
\text { to the scale }\end{array}$ & $\begin{array}{c}\text { Correlation } \\
\text { to the } \\
\text { domain }\end{array}$ \\
\hline 1 & $.760^{* *}$ & $.502^{* *}$ & 13 & $.420^{* *}$ & $.513^{* *}$ & 25 & $.354^{*}$ & $.820^{* *}$ \\
2 & $.542^{* *}$ & $.420^{*}$ & 14 & $.530^{* *}$ & $.530^{* *}$ & 26 & $.734^{*}$ & $.621^{* *}$ \\
3 & $.382^{*}$ & $.368^{*}$ & 15 & $.513^{* *}$ & $.513^{* *}$ & 27 & $.372^{*}$ & $.441^{*}$ \\
4 & $.510^{* *}$ & $.367^{*}$ & 16 & $.442^{*}$ & $.672^{* *}$ & 28 & $.418^{*}$ & $.384^{*}$ \\
5 & $.442^{*}$ & $.672^{* *}$ & 17 & $.640^{* *}$ & $.597^{* *}$ & 28 & $.620^{* *}$ & $.593^{* *}$ \\
6 & $.703^{* *}$ & $.395^{*}$ & 18 & $.411^{*}$ & $.603^{* *}$ & 30 & $.526^{* *}$ & $.419^{*}$ \\
7 & $.444^{* *}$ & $.555^{* *}$ & 19 & $.667^{* *}$ & $.532^{* *}$ & 31 & $.410^{*}$ & $.524^{* *}$ \\
8 & $.510^{* *}$ & $.367^{*}$ & 20 & $.620^{* *}$ & $.593^{* *}$ & 32 & $.447^{* *}$ & $.472^{* *}$ \\
9 & $.442^{*}$ & $.672^{* *}$ & 21 & $.526^{* *}$ & $.419^{*}$ & 33 & $.424^{*}$ & $.723^{* *}$ \\
10 & $.703^{* *}$ & $.395^{*}$ & 22 & $.410^{*}$ & $.524^{* *}$ & 34 & $.809^{* *}$ & $.801^{* *}$ \\
11 & $.444^{* *}$ & $.555^{* *}$ & 23 & $.380^{*}$ & $.534^{* *}$ & 35 & $.540^{* *}$ & $.375^{*}$ \\
12 & $.420^{* *}$ & $.513^{* *}$ & 24 & $.533^{* *}$ & $.730^{* *}$ & 36 & $.382^{*}$ & $.439^{* *}$ \\
\hline$*$ & statistically significant at significance level(0.05) & statistically significant at significance level (0.01)
\end{tabular}

Table 2. Correlation coefficients between the items, their domains, and the total score of the distance learning scale

\begin{tabular}{ccccccccc}
\hline Item \# & $\begin{array}{c}\text { Correlation } \\
\text { to the scale }\end{array}$ & $\begin{array}{c}\text { Correlation } \\
\text { to the } \\
\text { domain }\end{array}$ & Item \# $\begin{array}{c}\text { Correlation } \\
\text { to the scale }\end{array}$ & $\begin{array}{c}\text { Correlation to } \\
\text { the domain }\end{array}$ & Item \# $\begin{array}{c}\text { Correlation } \\
\text { to the scale }\end{array}$ & $\begin{array}{c}\text { Correlation to } \\
\text { the domain }\end{array}$ \\
\hline 1 & $.380^{*}$ & $.534^{* *}$ & 7 & $.419^{*}$ & $.593^{* *}$ & 13 & $.382^{*}$ & $.439^{* *}$ \\
2 & $.533^{* *}$ & $.730^{* *}$ & 8 & $.384^{*}$ & $.471^{* *}$ & 14 & $.510^{* *}$ & $.521^{* *}$ \\
3 & $.521^{* *}$ & $.612^{* *}$ & 9 & $.419^{*}$ & $.432^{*}$ & 15 & $.442^{*}$ & $.630^{* *}$ \\
4 & $.630^{* *}$ & $.530^{* *}$ & 10 & $.423^{*}$ & $.621^{* *}$ & 16 & $.424^{*}$ & $.723^{* *}$ \\
5 & $.526^{* *}$ & $.419^{*}$ & 11 & $.447^{* *}$ & $.472^{* *}$ & 17 & $.695^{* *}$ & $.395^{*}$ \\
6 & $.352^{*}$ & $.621^{* *}$ & 12 & $.424^{*}$ & $.723^{* *}$ & 18 & $.331^{*}$ & $.555^{* *}$ \\
\hline * statistically significant at significance level (0.05) ${ }^{* *}$ statistically significant at significance level (0.01)
\end{tabular}


It is clear from table (1) and table (2) that the correlation coefficients of the scale items =, their domains and the total scale score were all significant at significance level $\left(\bigotimes_{=0.05}\right)$ and $(\bigotimes=0.01)$. Therefore, no items were deleted.

\section{Reliability of the Research Instruments}

To ensure the reliability of the study scales, the reliability coefficient was calculated using the internal consistency according Cronbach's Alpha equation over a sample consisted of 15 male and female teachers that were excluded from the study sample.

The internal consistency coefficient for the domains of the educational crises management scale using Cronbach's Alpha was (0.84), where it was (0.82) using test-retest method. For the distance learning scale, the internal consistency coefficient for the scale domains using the Cronbach's Alpha was (0.86), where it was (0.84) using test-retest method (results are shown in table 3 ). These coefficients are acceptable for the purposes of the study and supporting the use of the scale in the current study.

Table 3. Reliability coefficients of the study scales using Cronbach's Alpha and test-retest method

\begin{tabular}{cccc}
\hline Measurement domain & Domain & Test-retest reliability & Cronbach's Alpha reliability \\
\hline Educational crisis & Planning & 0.84 & 0.86 \\
management & Data & 0.80 & 0.81 \\
& Communication & 0.83 & 0.85 \\
& Leadership skills & 0.81 & 0.84 \\
Distance learning & Team work & 0.82 & 0.84 \\
& Total & 0.82 & 0.84 \\
& Significance of distance learning & 0.80 & 0.83 \\
& Rationale of distance learning & 0.83 & 0.86 \\
& Barriers of distance learning & 0.81 & 0.84 \\
& Total & 0.84 & 0.86 \\
\hline
\end{tabular}

\section{RESULTS AND DISCUSSION}

Question one: What are the requirements of the educational crises management and its association to using distance learning method in the secondary stage schools in Al-Balqa'a governorate from the teachers' perspectives?

To answer the first research question, means and standard deviations for the responses on the educational crises requirements domains were calculated. Table (4) shows that.

Table 4. means and standard deviations for the educational crises requirements domains

\begin{tabular}{cccccc}
\hline$\#$ & Rank & Domain & M & SD & Level \\
\hline 1 & Planning & 3.93 & .582 & High \\
& 3 & Data & 3.75 & .630 & High \\
& 4 & Communication & 3.73 & .648 & High \\
2 & Leadership skills & 3.78 & .614 & High & High \\
\hline Total (educational crisis management requirements) & Team work & 3.72 & .657 & .636 & High \\
\hline
\end{tabular}


Table (4) shows that the mean scores for the domains of the educational crisis management requirements ranged between (3.72-3.93) that are at high levels, where the planning domain was ranked first with the highest mean score of (3.93), followed by leadership skills with a mean score of (3.78) And in the third rank was the information domain with a mean score of (3.75), and in the fourth rank was the communication domain with a mean score of (3.73), finally in the last rank was the team work with a mean score of (3.72). The mean score for the educational crisis management requirements scale as a whole was (3.76) with a high level and standard deviation (.636). The reason for this result is due to the fact that the availability of equipment alone is not sufficient to manage distance learning. Therefore, it is necessary to pre-plan to ensure the availability of administrative and technical equipment for work, and then provide information related to the equipment, the qualifications of the staff, the availability of electronic content, and then provide communication and leadership skills able to manage this project in light of the current outbreak, through a qualified and trained team to work from several separate places to ensure the proper progress and quality of the work. In this context, Hilali and Dabbous (2011) emphasize that educational crisis management needs a methodology for diagnosing crises, through knowledge, practice, and experience. The most important of them, are: the abundance of information and data for the decision-makers, as the diagnosis process is the real key to dealing with the crisis, and without it, dealing with crises becomes an emotional improvisation process. Thus, distance learning as a method for managing educational crises must be based on proper planning and good management of work teams. This - in my opinion - is consistent with Al-Oraifi's (2003) view that the poor educational quality, the cost of development, the absence of the national plan, the limited content in the market, and the absence of human interaction are among the most important obstacles facing distance learning. This finding was consistent with the Adams \& Kritsonis (2006) study that demonstrated the necessity of giving schools broad-based roles in crisis management, and Ghunaima's study (2014) that demonstrated the great importance of fulfilling educational crisis management requirements in secondary schools.

Second question: what is the level of applying distance learning by the secondary stage schools in Al-Balqa'a governorate during the COVID-19 outbreak from the teachers' perspectives?

To answer the second research question, means and standard deviations of the teachers' responses for the domains of the distance learning scale were calculated. Results are shown in table (5)

Table 5. means and standard deviations for the domains of the distance learning scale

\begin{tabular}{cccccc}
\hline \multirow{2}{*}{$\#$} & Domain & M & Rank & SD & Level \\
\hline & Significance of distance learning & 3.62 & 2 & .610 & Medium \\
& Rationale of distance learning & 3.64 & 1 & .579 & Medium \\
& Barriers of distance learning & 3.58 & 3 & .743 & Medium \\
\hline Total (Distance learning) & & 3.59 & & .687 & Medium \\
\hline
\end{tabular}

Table (5) shows that the mean scores ranged between (3.56-3.64) at moderate levels, so that the rationale for distance learning method domain got the highest mean score (3.64), followed by the importance of distance learning method with a mean score of (3.62), and in the third and last rank was the obstacles of the distance learning method with a mean score of (3.58). The total mean score for the distance learning method was (3.59) and a standard deviation (.687), and with moderate level. This result is logical; there are many educational, health and preventive justifications that Teachers consider it when justifying the application of distance learning as one of the pedagogical methods for facing and managing the current crisis; Distance learning here is the best option for the ministry to protect the students and teachers, and it is an educational pattern that provides effective solutions capable of sustaining and diversifying education, and applying effective evaluation, to ensure that students do not stop their studies, and the teachers' performance of their duty, especially if proper planning is practiced to reduce the obstacles that may hinder the application of distance learning and ensure its success to face the current crisis. 
The importance of distance learning and its rationale - especially during the crisis - can be illustrated by what UNESCO studies on distance education have shown as one of the most developed fields in the recent period, as a result of the accelerated development of information and communications technology and its implications in the field of education, as well as in the design and provision of Educational systems through the Internet, in addition to the increasing social demand for school education in response to the demands of development plans (Al-Sunbul, 2001).

This result was in agreement with the study of Al-Sharhan (2014), which showed the importance of distance learning and the rationale for its application because of its great educational and social benefits, and $\mathrm{Al}-$ Hajri's study (2014) which showed the importance of applying the e-learning method as a tool for developing education

Third question: Is there is significant association between the requirements of the educational crises management and the distance learning method during the COVID-19 outbreak from the teachers' perspectives?

To answer this question, Pearson's correlation coefficient between the participants; responses on the requirements of the educational crises and the distance learning method, based on the responses of the study participants. Table (6) shows the results.

Table 6. Pearson's correlation coefficient for the association between the educational crises requirements and the distance learning

\begin{tabular}{clcccc}
\hline Correlation & & $\begin{array}{c}\text { Significance } \\
\text { of distance } \\
\text { learning }\end{array}$ & $\begin{array}{c}\text { Rationale } \\
\text { of distance } \\
\text { learning }\end{array}$ & $\begin{array}{c}\text { Barriers of } \\
\text { distance } \\
\text { learning }\end{array}$ & $\begin{array}{c}\text { Total } \\
\text { (Distance } \\
\text { learning) }\end{array}$ \\
\hline Planning & Correlation factor (R) & $.348^{* *}$ & $.387^{* *}$ & $.305^{* *}$ & ${ }^{* * 3} 345$ \\
Data & Correlation factor (R) & $.319^{* *}$ & $.334^{* *}$ & $.303^{* *}$ & $.328^{* *}$ \\
Communication & Correlation factor (R) & $.352^{* *}$ & $.398^{* *}$ & $.326^{* *}$ & $.329^{*}$ \\
$\begin{array}{c}\text { Leadership skills } \\
\text { Team work }\end{array}$ & Correlation factor (R) & $.361^{* *}$ & $.323^{*}$ & $.392^{* *}$ & $.301^{*}$ \\
$\begin{array}{c}\text { Total (Educational crisis } \\
\text { management requirements) }\end{array}$ & Correlation factor (R) & $.327^{* *}$ & $.346^{*}$ & $.331^{* *}$ & $.315^{*}$ \\
\hline
\end{tabular}

*tatistically significant at significance level (0.05) ** statistically significant at significance level (0.01)

Table (6) shows the role of the requirements of educational crisis management in its five domains (planning, information, communications, leadership skills, team work) in raising the level of use of the distance learning method in its three domains (the importance of distance learning, the rationale for distance learning, and the obstacles to distance learning) among male and female teachers of secondary schools in Al Balqa'a governorate. This result is considered logical, proper planning and availability of information and logistical and technical capabilities ensure the success of the distance learning process and enables the educational sector to face the educational crisis and manage it more effectively.

In addition to the planning, information, the availability of communication channels and the formation of qualified and trained work teams, and the presence of effective leaders increases the importance of distance learning, and makes it more attractive and effective. Therefore, there are logical justifications for its application, and that the availability of these requirements will enable the Jordanian educational system to get rid of all obstacles and the problems that hinder the application of distance learning and limit its effectiveness. Consequently, the success of distance learning is linked to the availability of educational requirements to manage the educational crisis and reduce the obstacles to application.

In this context, $\mathrm{Al}$-Zameli and others (2007) indicated that due to the seriousness of the results of crises of all kinds, educational institutions are keen to use various strategies, emphasizing participation with workers in the institution or school, and collective leadership in thinking, implementation, and then follow-up and evaluation, in addition to activating that by forming committees and task forces, organizing crisis data and 
preparing and training individuals to face them. Dealing with crises requires the presence of a special type of managers, teachers and administrators who are adequately trained, to refine their skills, talents and natural preparedness, as dealing with crises has a special character that derives its specificity from the impact of future momentary factors with their confrontational dimensions, as well as the possibilities of deteriorating conditions in a very strong way (Hamdouneh, 2006)

This result was consistent with the study of Al-Hersh, Mufleh and Al-Dahoon (2010), which indicated the need for proper planning and implementation of e-learning success, while recommending the necessity of qualifying and training work teams. In addition, this result id in line with Khubrani's (2014) study findings, which showed that the most important methods of crisis management are the scientific method in the first rank, then the style of the team work, and that the most important obstacles facing the use of crisis management methods are: the large number of tasks assigned to the school principal and the routine nature related to it, in addition to the lack of a Comprehensive database in the field of school crisis management, and therefore it is necessary to have proper planning to ensure the success of the process and reduce its obstacles.

\section{RECOMMENDATIONS}

1. For researchers, it is recommended to perform more extended studies investigating the availability of the crisis management requirements in the educational context, and linking this availability to using distance learning in the educational process. This type of research would give a better insight into the preparedness of the educational institutions for any expected crisis and evaluate the institution preparedness for the emergency cases.

2. The current study recommends performing training workshops and courses to equip the educational practitioners with the skills required to employ the educational crisis management requirements in distance learning.

3. The necessity of enhancing the awareness of school principals and teachers of the importance of educational crisis management and its advance planning and their role in resolving crises and overcoming them in the school environment and post occurrence.

4. Conducting seminars and lectures by the Education Department for school principals about some expected crises and how to deal with them, and setting ways to avoid problems facing the educational process.

5. Develop a clear plan for the system of distance learning that includes: the definition of the system, its objectives, the means of its application and its application stages.

6. The need to pay attention to schools in terms of the necessary preparation and provide the necessary equipment and tools in light of technological developments to overcome crises and the ability to cope with them.

7. Qualifying and developing the multiple competencies that must be met by the parties of the educational system in a way that allows them to perform their various roles according to the methods of distance education. 


\section{BIODATA and CONTACT ADDRESSES of AUTHOR}

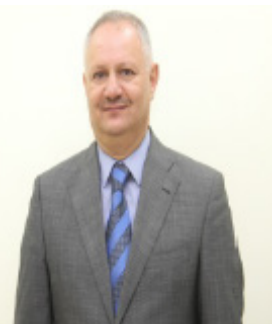

Dr. Fadi SAMAWI is an Associate Professor of educational psychology at Al-Salt college of Humanitarian Sciences, Al-Balqa Applied University. Dr. Samawi gained his Ph.D. in Educational Psychology at July, 2010. His academic interest areas are educational psychology, talented and gifted students educational research, designing and planning counselling programs for gifted students and counselling and mental health field. He has over than 12 journal articles published in international indexes, and other national and international articles, papers submitted to international meetings.

Fadi SAMAWI

Department of Educational Psychology, Al-Salt college of Humanitarian Sciences

Address: Al-Balqa Applied University, 19117, Al-Salt, Jordan

Phone: +962 777420609

E-mail: fadi.samawi@bau.edu.jo

\section{REFERENCES}

Abdulaziz, H. (2008). E-Learning Philosophy - Principles - Tools - Applications, Oman: Dar Al Fikr.

Abu Khalil, M. (2001). The role of principals of basic education schools and planning to face them, Future of Arab Education Journal, 7(21), 259-318.

Adams, Cheantel M \& Kritsonis, William Allan, (2006), Analyzing secondary school crisis. National Journal for Publishing and Mentoring, Vol (1), No (1).

Al-Oreifi, Y. (2003). E-learning is a promising technology and a pioneering method, e-learning seminar, dated 24/2/2003, King Faisal Schools, Riyadh.

Al-Hajri, M. (2016). The attitudes of the teaching staff and students towards the application of e-learning: A field study in the Ministry of Education in the State of Kuwait - secondary stage, the General Authority for Applied Education and Training to support research, 6(13), 1-85.

Al-Hersh, A., M, M., Al-Dahoon, M. (2010) Barriers to using the e-learning system from the viewpoint of secondary school teachers in Al-Koura District, Jordanian Journal of Educational Sciences, 6(1), $27-40$.

Al-Khubrani, A. (2014). Methods of school crisis management in the stages of public education, and the obstacles to their use in the city of Makkah Al-Mukarramah from the point of view of school principals, College of Education, Umm Al-Qura University, Saudi Arabia.

Al-Khudairi, M. (2003). Crisis Management: An Administrative Economic Approach to Resolving Crises at the Egyptian Economic Level and Economic Unity, Madbouly Library, Cairo.

Al-Kloob, B. A. (1993). Technology in the educational process, Dar Al-Alam, Amman, Jordan.

Al-Mahdi, S., Wahiba, H. (2002). Behavioral practices of school administrators in dealing with crises within the school, Journal of the College of Education and Psychology, 26 (4), 143-221.

Al-Musa, N. (2007). Crisis Management in Public Education Schools in Riyadh - A Proposed Conception, Unpublished Doctorate Thesis, College of Education, King Saud University, Saudi Arabia.

Al-Omar, N. S. (2003). Dialogue entitled: Approaches to Prosperity do not produce crisis leaders, the statement, No. (184).

Al-Saadat, K. (2002). The possibility of using distance education in the programs of the College of Applied Studies and Community Service at King Faisal University in Al-Ahsa - an exploratory study, Damascus University Journal, 12(1), 175-217.

Al-Shaikh, B. The extent to which security and safety management is ready to face crises and disasters, MA, Naif Arab University for Security Sciences, Riyadh 
Al-Sharhan, S. (2014). Open Education and Distance Learning in the Arab World towards Development and Creativity, a study presented to the Fourteenth Conference of Ministers Responsible for Higher Education and Scientific Research in the Arab World, January 2014, Gulf University for Science and Technology, Kuwait.

Al-Sunbul, A. A. (2001). The justifications for adopting the distance learning system in the Arab world, the Journal of Education, the National Committee for Education, Culture and Science of the Arab Organization for Education, Culture and Science, Qatar, September, 137, (2001), 84.

Al-Tawil, H. (2006). Educational Administration: Concepts and Prospects, First Edition, Wael Press for Printing and Publishing, Amman.

Al-Zamili, A., Al-Ghanbousi, S., Suleiman, S. (2007), School crises and methods of dealing with them in schools in the Sultanate of Oman, Journal of Educational and Psychological Sciences, 8(3), 64-84.

Bani Domi, H., Al-Shannaq, Q. (2007). The obstacles of e-learning in Jordanian secondary schools from the viewpoint of teachers and students, a research paper submitted to the International Conference on Distance Education, Muscat, and March 27-29, 2007.

Bundy, J., Cole, P., \& Coombs, T. (2017). Crises and Crisis Management: Integration, Interpretation, and Research Development. Journal of Management, 43(6) , 1661 -1692.

Chi Keung, Cheng, (2008) The Effect of Shared Decision-Making on Improving and Developing Teachers' Jobs》 Access date, October (14), (2009), from: http://www.eric.ed.gov.

Eliwa, S. (2004). Crisis and Disaster Management Risks of Globalization and International Terrorism, Decision Making Manual Series (2), Dar Al-Ameen for Publishing and Distribution, Cairo.

Ghunima, R. M. (2014). The requirements of educational crisis management in secondary schools in the city of Damascus, unpublished master's thesis, University of Damascus, Syrian Arab Republic.

Hamdouna, H. (2006). Principals of the Secondary School Practice of Crisis Management Skill in Gaza Governorate, Unpublished Master Thesis, College of Education, Islamic University, Gaza.

Hasaneen, K. (2004). The concept of distance education, Sudan Open University, A research paper May 2004, p. 1.

Hilali, H., Dabbous, M. (2011). Educational crises in government secondary schools in northern Palestine and how to manage them from the perspectives of administrators, An-Najah University Journal for Research (Humanities), 25 (5), 1160-1187.

Integrated Technology Group (2006). Integrated e-learning system for the Arab world, Source: www.itgsolution. com, retrieved 21/6/2020.

Kamei, K. (2019). Crisis Management. Science of society Safety, 1(1), 141-150.

Khazaleh, T. And Jawarneh, T. (2006). Barriers to effective information technology integration in Jordanian schools as perceived by in-service teachers. Jordan Journal of Educational Sciences, 2(4): 281-292.

Mostafa, Y. (2005), Educational Administration: New approaches to a New World, First Edition, Dar Al-Fikr Al-Arabi, Egypt.

Picciano, Anthony E., (2001). Distance learning making connections across virtual space and time. New Jersy: Merill Prentice Hall.

Ryan, R. (2007). The Effects of Web-Based Social Networks on Student Achievement and Perception of Collaboration at the Middle School Level. (Dissertation submitted to the College of Education at Touro University Cypress California International in partial fulfillment of the requirements for the degree of Doctor of Philosophy in Educational Leadership).

Sabbah, Y. (2010). E-learning and information and communication technology in education in Palestinian schools: the path towards 21 st century skills, Palestinian Journal of E-learning and Open Learning, 8(14), 1-16. 
Salem, R. (2007). Educational Technology. Amman: Arab Society Library.

Saqr, A. M. (2009). The degree of availability of crisis management skills to school administrators, UNRWA, and ways to develop them, unpublished Master Thesis, College of Education, Islamic University, Gaza.

Shery, L., (2004). Issues in Distance Learning, International Journal of Educational Telecommunications, 1: 337-365.

Simpson, Ormond, (2000), Supporting students in Open and Distance Learning, London: Kogan Page.

Tony Kaye, (1991(. Greville Rumble. Open Universities: A Comparative Approach. Prospects. 21(2).

USDLA. (2004). (US American Distance Education Association), Definition of Distance Learning. http// www.usdla.org/. (Accessed June, 6,2004). 